\title{
Processo 'Parcialmente Imparcial': os Estados Unidos como Mediadores das Negociações de Paz entre Israel/Palestina.
}

'Partially impartial' Process: the United States as the peace talks mediators between Israel/Palestine.

\section{Claudia Stephan 1}

\section{RESUMO}

O artigo analisa a parcialidade dos Estados Unidos (EUA) como mediadores das negociações "de paz" entre Israel/Palestina. O objetivo é desvelar a parceria estratégica entre os EUA e Israel e suas consequências para uma solução permanente do conflito. Conclui-se que essa parcialidade favorece os interesses de Israel, estagnando o processo de negociações, em detrimento de uma solução de dois Estados.

Palavras-chave: Estados Unidos; Israel; Mediação das negociações de paz.

\begin{abstract}
The article analyses the United States (US) bias as the peace talks mediators between Israel/Palestine. The aim is to unveil the strategic partnership between the US and Israel and its consequences for a permanent solution to the conflict. In conclusion, this bias favors the interests of Israel by stalling the negotiations process rather than advancing a twostate solution.
\end{abstract}

Keywords: United States; Israel; Peace negotiations mediation.

\section{Introdução}

A atual situação de naturalização da violência em Israel/Palestina, noticiada quase que diariamente no mundo todo, parece refletir a ineficácia do sistema de segurança coletivo da ONU em solucionar permanentemente o conflito árabe-israelense. Entretanto, e devido à sua complexidade, há uma dimensão mais normativa do conflito, geralmente obscurecida pela mídia, que não é enfatizada nessas análises: a parceria

\footnotetext{
1 Internacionalista, MSc. em Ciência Política (PPGCP/UFPR), membro do NEPRI/UFPR e coordenadora do GESEG/UFPR - Curitiba, PR - Brasil. Contato: claudia.stephan@hotmail.com

Conjuntura Global, Vol.3, n. 4, out./dez., 2014, p. 184-193. 
estratégica entre os Estados Unidos (EUA) e Israel e suas implicações para o processo de negociações "de paz".

0 paradoxo da existência de diversas normas internacionais que pretendem resolver o conflito, dentre elas as do Direito Internacional Humanitário (DIH), do Direito Internacional dos Direitos Humanos (DIDH), do Direito Internacional dos Refugiados (DIR) e as próprias resoluções da ONU aplicáveis ao caso, e de uma realidade de contínuo descumprimento dessas normas/resoluções é preocupante para o futuro de palestinas e palestinos, bem como de cidadãs/cidadãos árabe-israelenses ${ }^{2}$ no que diz respeito à solução de dois Estados, principalmente quando o lado mais forte (Israel) tem apoio incondicional de uma das grandes potências mundiais (EUA). 0 apoio estadunidense a Israel seria apenas mais uma nuança da política e das relações internacionais, não fosse por um detalhe: a parcialidade dos EUA como mediadores no processo de negociações de paz entre a Autoridade Nacional Palestina e o Estado israelense.

A análise dessa parcialidade exige uma breve introdução do conceito de mediação internacional e de seus princípios fundamentais, a fim de fundamentar o questionamento acerca da imparcialidade dos atores/Estados ${ }^{3}$ no processo de negociações "de paz" entre Israel/Palestina.

Segundo a Organização das Nações Unidas (ONU),

a mediação é um método de solução pacífica de uma disputa internacional no qual um terceiro intervém para conciliar as reivindicações das partes em controvérsia e para avançar suas próprias propostas no sentido de um compromisso para uma solução mutuamente aceitável. [...] Assim, a mediação como método de resolução pacífica é mais do que um complemento para as negociações. Como pode ser visto, por exemplo, na prática das Nações Unidas, tornou-se um método diferente para facilitar um diálogo entre as partes em uma controvérsia internacional, com o objectivo de minimizar as hostilidades e tensões e para alcançar, por meio de um processo político controlado pelas partes, uma solução amigável de uma disputa internacional.

[...] Por sua própria existência, um processo de mediação tem impacto sobre o equilíbrio de poder e os cálculos políticos dentro e entre diferentes grupos. Mediadores e a comunidade internacional, como atores de apoio, precisam ser sensíveis a ambos os impactos positivos e os potencialmente negativos de um

\footnotetext{
2 "Há mais de 50 leis israelenses que discriminam os cidadãos palestinos de Israel em todas as áreas da vida, incluindo seus direitos de participação política, acesso à terra, educação, recursos do Orçamento do Estado e procedimentos penais. Algumas das leis também violam os direitos dos palestinos que vivem nos territórios ocupados de 1967 e refugiados palestinos" (ADALAH, 2014). Disponível em: http://adalah.org/eng/Israeli-Discriminatory-Law-Database.
}

${ }^{3} 0$ artigo apenas analisa os Estados Unidos, devido ao recorte imposto pelo limite de páginas.

Conjuntura Global, Vol.3, n. 4, out./dez., 2014, p. 184-193. 
processo de mediação. Mediadores precisam manter a opção de colocar o seu envolvimento em espera ou se retirar. Isto pode ser apropriado se considerarem que as partes estejam negociando de má-fé, se a solução em evolução está em desacordo com as obrigações legais internacionais, ou se outros atores estão manipulando o processo e limitando o espaço de manobra do mediador. No entanto, esta é uma decisão política sensível que deve pesar os riscos de retirada contra o valor de manter as partes à mesa em um processo estagnado, enquanto explora meios alternativos para a solução pacífica de controvérsias (UN HANDBOOK ON THE PEACEFUL SETTLEMENT OF DISPUTES BETWEEN STATES, 1992, p. 40-41; UN GUIDANCE FOR EFFECTIVE MEDIATION, 2012, p. 5 - sem grifo no original).

Os princípios fundamentais da mediação internacional são: preparação, consentimento, imparcialidade, inclusão, apropriação nacional, direito internacional e quadros normativos, coerência/coordenação/complementaridade do esforço de mediação e acordos de paz qualificados ${ }^{4}$ (UN GUIDANCE FOR EFFECTIVE MEDIATION, 2012, p. 6-22 - sem grifo no original). Nesse sentido, destaca-se o princípio da imparcialidade como imprescindível para o sucesso das negociações, uma vez que sua ausência no processo implica beneficiar a priori uma das partes em controvérsia.

Como ator constante de iniciativas de paz e rodadas de negociações, juntamente com outros atores como a União Europeia, a Liga Árabe e a própria ONU, é imprescindível repensar a participação dos EUA a partir de três pontos interligados e fundamentais:

- Imparcialidade do(s) mediador(es) do processo "de paz";

- Incentivo ao cumprimento das normas internacionais (DIH, DIDH, DIR e resoluções da ONU aplicáveis ao conflito); e

- Financiamento militar para uma das partes negociantes pelo(s) mediador(es).

A análise desses pontos facilitará a compreensão acerca da estagnação do processo de paz, bem como seu fracasso. Vale ressaltar que alguns acordos entre Israel/Palestina foram assinados no passado ${ }^{5}$, mas não cumpridos por Israel. Resta

\footnotetext{
${ }^{4}$ Para uma definição de cada um desses princípios, acessar o link nas referências bibliográficas.

5 The Oslo Accords, 1993; Israeli-Palestinian Interim Agreement on the West Bank and the Gaza Strip, 1995; Camp David Accords, 2000.

Conjuntura Global, Vol.3, n. 4, out./dez., 2014, p. 184-193. 
verificar quais são as consequências, imediatas e futuras, dessa parcialidade para uma solução permanente do conflito, incluindo a questão dos refugiados palestinos ${ }^{6}$.

\section{Parcialidade dos Estados Unidos como mediadores do processo de paz}

A participação dos EUA como mediadores nas negociações "de paz" entre Israel e Palestina é uma constante desde os primórdios do conflito. Mas, como é possível que um Estado que apoia incondicionalmente uma das partes negociantes seja aceito como mediador pela comunidade internacional, uma vez que um dos princípios da mediação é a imparcialidade? A relação entre os EUA e Israel não é novidade, mas tem se estreitado com os últimos enfrentamentos na região graças ao lobby judaico. A proposta mais recente é o United States-Israel Strategic Partnership Act of 2014:

O Congresso dos EUA aprovou o Ato de Parceria Estratégica Estados UnidosIsrael de 2014 no início de dezembro. O Senado aprovou o projeto de lei em setembro e a etapa final para se tornar lei será a assinatura do Presidente antes de ser promulgada dentro de alguns dias. [...] A nova lei oferecerá privilégios significativos para Israel em muitos aspectos da sua relação com a América. 0 mais importante é que ela muda o apoio político da América para Israel; haverá um compromisso legal de garantir a superioridade militar de Israel, tornando-o "mais forte do que todos os seus adversários combinados". Esta lei também determina um aumento no número de armas americanas armazenadas em Israel para serem usadas durante períodos de emergência, no valor de cerca de US $\$ 2$ bilhões de dólares em vez dos atuais US\$200 milhões. [...] Significa que Israel se junta ao exclusivo clube de países que recebem tratamento especial dos Estados Unidos em termos de facilitar os procedimentos para as visitas e as áreas de cooperação e coordenação. Ao passar do projeto para a lei, uma cobertura legal está sendo dada aos privilégios que, na verdade, já são oferecidos para Israel (MAKSOUD, 2014).

No manual da ONU sobre mediação internacional, United Nations Guidance for Effective Mediation, imparcialidade é definida como:

[...] uma pedra angular da mediação - se um processo de mediação é percebido como tendencioso, isso pode minar significativamente o progresso para resolver $o$ conflito. Um mediador deve ser capaz de executar um processo equilibrado, que trata de todos os atores de maneira justa e não deve ter interesse material no resultado. Isso também exige que o mediador seja capaz de falar com todos os atores relevantes para a resolução do conflito (2012, p. 10 - sem grifos no original).

\footnotetext{
6 Segundo Said (2000), existem três instrumentos que garantem o direito de retorno aos refugiados palestinos: a Resolução 194 da Assembleia Geral da ONU de 1948 (11 ${ }^{\circ}$ artigo), a Declaração Universal dos Direitos Humanos $\left(13^{\circ}(2)\right.$ e $17^{\circ}(2)$ artigos) e a $4^{\text {a }}$ Convenção de Genebra (49 artigo).

Conjuntura Global, Vol.3, n. 4, out./dez., 2014, p. 184-193. 
Segundo esse manual, a imparcialidade "não é sinônimo de neutralidade, uma vez que, como mediador, especialmente da ONU, é tipicamente ordenado a seguir certos princípios e valores universais e pode precisar aclará-los às partes" (UN GUIDANCE FOR EFFECTIVE MEDIATION, 2012, p. 10). Entretanto, imparcialidade e neutralidade são, sim, sinônimos em dicionários da língua portuguesa e da língua inglesa, o que implica "equidade, isenção, justiça", independentemente dos princípios e valores universais dos mediadores (CALDAS AULETE, 2014; OXFORD, 2014). Portanto, mediadores que mantêm parcerias estratégicas com uma das partes em negociação estão sujeitos ao questionamento de parcialidade, uma vez que possuem interesses e objetivos em comum - especialmente com a aprovação da nova lei de parceria estratégica de 20147 .

Essa parcialidade influencia tanto nas decisões dos negociadores mais fortes, pois contam com o suporte de uma grande potência hegemônica, quanto nas decisões dos negociadores mais fracos, já que tendem a fazer concessões em pontos fundamentais, a fim de chegar a um acordo final mais rapidamente. No caso das negociações entre Israel/Palestina, a parcialidade do mediador reforça tanto a posição favorável de Israel quanto a posição vulnerável da Autoridade Nacional Palestina (ANP), uma vez que os EUA não apenas posicionam-se politicamente a favor do Estado ${ }^{8}$ mais forte, mas também diplomaticamente na ONU, via Assembleia Geral das Nações Unidas (AGNU) e Conselho de Segurança das Nações Unidas (CSNU), e financeiramente por meio de financiamento militar para Israel.

A continuidade de mediadores parciais neste processo de negociações certamente coloca ainda mais em risco uma solução de dois Estados, já que os recorrentes fracassos em assinar um acordo final viabilizam a ocupação de novas áreas palestinas por Israel, como tem ocorrido regularmente desde 1967, inviabilizando a implantação do Estado Palestino sem que haja grandes retrações de fronteiras e deslocamentos de assentamentos judaicos. Há, portanto, uma urgente necessidade de novos atores (imparciais) comprometidos com o estabelecimento imediato de um

\footnotetext{
7 A última parceria EUA-Israel foi assinada pelo Presidente Barack Obama em dezembro de 2014, tornando-se lei. Para ver a lei 'Public Law No: 113-296', acesse: https://www.congress.gov/bill/113thcongress/senate-bill/2673/text.

${ }^{8}$ Lembrando que a Palestina ainda não é reconhecida como Estado na ONU, apenas simbolicamente reconhecida por diversos países.

Conjuntura Global, Vol.3, n. 4, out./dez., 2014, p. 184-193. 
Estado Palestino, sem a parcialidade de financiamentos militares, venda de armamentos e pressões constantes do lobby judaico-sionista.

\section{Facilitação dos EUA para o descumprimento do DI e das resoluções da ONU}

O sucesso de uma negociação de paz depende de vários fatores, como o interesse das partes negociantes, posicionamento dos líderes, pressão da opinião pública, capacidade militar do Estado, pressão e mobilização da comunidade internacional dentro e fora da ONU, entre outros.

É possível afirmar que há interesse da parte palestina em negociar um acordo final, com o estabelecimento de um Estado nas fronteiras anteriores à ocupação militar israelense de $1967^{9}$. Há também pressão da opinião pública, que vem aumentando nos últimos anos devido à violência institucionalizada e frequentes agressões militares israelenses, bem como mobilização da comunidade internacional, via ONU/AGNU, para o cumprimento dos acordos assinados e para uma negociação final, e uma atual pressão pelo reconhecimento da Palestina como Estado por diversos países ${ }^{10}$.

Entretanto, Israel não tem demonstrado interesse real em resolver permanentemente o conflito, mas apenas retórico, além da nítida vantagem de ser um Estado reconhecido pela comunidade internacional na ONU e com grande capacidade militar. E, ainda que venha a se posicionar verdadeiramente a favor de um acordo permanente, seu poder político e militar é superior ao da ANP e seu posicionamento é oposto ao dos palestinos - vide atual proposta de instituição do caráter judaico em Israel, significando uma mudança de Estado "democrático" para Estado teocrático, com todas as implicações dessa possível mudança ${ }^{11}$.

Nesse sentido, uma parceria estratégica entre um Estado com poder de veto no CSNU e um Estado/ator parte de um processo de negociação "de paz" pode garantir não apenas vantagens, mas também o adiamento necessário para a manutenção do status quo e/ou avanço de seus interesses, criando ou facilitando estratégias em detrimento da

\footnotetext{
${ }^{9}$ Israel ocupa a Península do Sinai, a Faixa de Gaza, a Cisjordânia e as Colinas de Golã em 1967, na Guerra dos Seis Dias, ignorando mais uma resolução da ONU, a Resolução 242 do CSNU, a qual exigia a retirada das tropas israelenses das áreas ocupadas e negociação de fronteiras permanentes.

${ }^{10}$ A Suécia reconheceu a Palestina como Estado em 2014, e há uma recente onda de pressão e mobilização dos parlamentos europeus aos seus governos para seguir o mesmo caminho.

${ }^{11}$ As implicações não serão abordadas aqui, devido ao limite de páginas do artigo.

Conjuntura Global, Vol.3, n. 4, out./dez., 2014, p. 184-193. 
outra parte negociadora. No caso de Israel/Palestina, essa parceria estratégica está estabelecida desde os primórdios do conflito e das próprias negociações, por exemplo, com inúmeros vetos dos EUA às resoluções da AGNU e do CSNU que criticam ou condenam Israel.

Esse posicionamento irredutível dos EUA facilita o descumprimento do direito internacional e das resoluções da ONU aplicáveis ao conflito, uma vez que as recomendações aprovadas na AGNU, mesmo com o voto contrário norte-americano, não possuem caráter coercitivo e as decisões do CSNU que o possuem são vetadas pelo seu parceiro estratégico em favor de Israel.

Dessa maneira, facilita-se o descumprimento das normas internacionais por Israel, já que conta com o apoio incondicional dos EUA na principal via de cooperação e segurança coletiva e a garantia de defender seus interesses publicamente, enquanto expande seu território e seus interesses em detrimento de uma solução permanente para a situação vulnerável em que se encontram milhões de palestinas e palestinos. Portanto, é possível considerar o discurso dos EUA retórico, no que diz respeito ao cumprimento das normas internacionais pelos Estados, em especial nas questões que envolvem o conflito entre israelenses e palestinos - algo como "faça o que eu digo, mas não faça o que nós fazemos, ou haverá consequências!".

\section{Financiamento Militar Estrangeiro $(F M F)^{12}$ dos EUA para Israel}

Uma última questão relevante para repensar a imparcialidade no processo de negociações "de paz" é o financiamento militar dos EUA para Israel. Sabe-se que as relações internacionais envolvem parcerias estratégicas comerciais, diplomáticas, tecnológicas, militares etc., mas quando se trata de uma questão de segurança internacional parece oportuno que a comunidade de Estados avalie as implicações de uma relação entre mediadores e negociadores. Afinal, para que o processo de negociações seja imparcial, é necessário que nenhuma das partes negociadoras seja previamente e/ou continuamente beneficiada pelo(s) mediador(es).

12 Foreign Military Financing.

Conjuntura Global, Vol.3, n. 4, out./dez., 2014, p. 184-193. 
Nesse sentido, como é possível que mediadores como os EUA, que apoiam publicamente e incondicionalmente uma das partes - Israel, além de financiá-la militarmente, sejam aceitos e mantidos como tal por tantas décadas? Como é possível pensar em imparcialidade diante dessa parceria estratégica? O Estado responsável pela mediação de um conflito é o mesmo que financia o aparelho militar que sustenta essa situação por décadas, naturalizando a violência contra a outra parte negociadora e, ao mesmo tempo, reiterando seu discurso "de paz" e respeito aos direitos humanos e às normas internacionais. "Israel tem sido o maior beneficiário da assistência de segurança dos EUA desde o início dos anos 1970, quando a administração Nixon aumentou dramaticamente a ajuda militar para o país e cimentou a estreita relação que perdura até hoje" (BERRIGAN, 2009, p. 6).

\begin{abstract}
Israel recebe a maior parte da sua ajuda militar dos EUA por meio do Financiamento Militar Estrangeiro (FMF), que é uma assistência para compras de armas. Mas esta não é a totalidade do apoio dos EUA a Israel. Pelo menos tão valioso é o tratamento especial que vem com os bilhões de dólares em subvenções. Israel é o único país autorizado a utilizar uma parte substancial da sua ajuda militar dos EUA para construir sua indústria doméstica militar, um privilégio que inclui o desenvolvimento de sistemas de armas indígenas baseados em desenhos norte-americanos e com recursos da FMF para compra de material, bem como pesquisa e desenvolvimento de empresas em Israel. Os fundos adicionais dos EUA são gastos em pesquisa militar conjunta e produção, tais como sistemas de defesa de mísseis anti-balísticos e até mesmo aviões de combate. Enquanto outros países obtêm a sua FMF distribuída em loteamentos trimestrais, Israel recebe tudo isso de uma só vez no início do ano. Esta prática cria uma carga de empréstimo para o governo dos Estados Unidos, uma vez que necessita de empréstimos do Tesouro dos Estados Unidos muito antes de o Congresso realmente liberar as verbas prometidas. Junto com um punhado de outras nações, Israel goza do status "fast-track" para a venda de armas, o que significa que ele pode perfeitamente passar o intermédio do Pentágono, envolvendo procedimentos complexos e atrasos, para fazer negócios diretamente com os fabricantes. Não é possível quantificar todas essas regalias em dólares, mas o que é indiscutível é que elas somam uma relação muito especial (BERRIGAN, 2009, p. 6-7).
\end{abstract}

Os EUA "alimentam" um ciclo vicioso e destrutivo para ambas as partes, mas principalmente para os palestinos: disponibiliza bilhões em financiamento militar para Israel que, por sua vez, mantém e aumenta sua capacidade militar; esse aparelho militar é responsável pela ocupação de terras palestinas, pela remoção daquele(as) que ali viviam, pela destituição de seus bens, pelas restrições de ir e vir e de acesso à educação, à saúde e ao trabalho em partes da Cisjordânia - por meio de checkpoints e roadblocks, mas principalmente pelo bloqueio à Faixa de Gaza; além disso, e muito mais 
preocupante, é responsável pela institucionalização da violência - por meio de incursões em residências palestinas, prisões administrativas sem mandado ou acesso à justiça, prisões de mulheres e crianças, além das inúmeras mortes, muitas vezes em ataques a grupos de protesto pacíficos ${ }^{13}$; tudo isso sem contar os recorrentes ataques militares à Gaza; justifica-se publicamente como autodefesa e, novamente, recebe financiamento militar. Entretanto, mesmo sendo corresponsáveis pela atual situação em Israel/Palestina, os EUA atuam como mediadores do processo "de paz".

Finalmente, após analisar esses três pontos fundamentais para o questionamento da imparcialidade nas negociações "de paz" entre Israel/Palestina, é possível concluir que a parcialidade dos EUA como mediadores favorece os interesses de Israel ao estagnar o processo em detrimento de uma solução de dois Estados, viabilizando o avanço da ocupação militar e a institucionalização da violência para conter qualquer resistência palestina.

\section{REFERÊNCIAS BIBLIOGRÁFICAS}

DICIONÁRIO Caldas Aulete digital. Disponível em: http://www.aulete.com.br/. Acesso em: $14 / 12 / 2014$.

DICIONÁRIO Oxford digital. Disponível em: http://www.oxforddictionaries.com/us. Acesso em: 14/12/2014.

BERRIGAN, Frida. Made in the U.S.A.: American Military Aid to Israel. Journal of Palestine Studies vol. xxxviii, n. 3 (Spring 2009), pp. 6-21.

MAKSOUD, Clovis. Congress and the US-Israel 'strategic partnership' - Middle East Monitor, 11 December 2014. Disponível em:

https://www.middleeastmonitor.com/articles/middle-east/15772-congress-andthe-us-israel-qstrategic-partnershipq. Acesso em: 14/12/2014.

UNITED NATIONS - Handbook on the Peaceful Settlement of Disputes between States, Office of Legal Affairs Codification Division. New York: 1992, p. 238. Disponível em: http://legal.un.org/cod/books/HandbookOnPSD.pdf. Acesso em: $14 / 12 / 2014$.

\footnotetext{
${ }^{13}$ Recentemente, no dia 10 de dezembro de 2014, o Ministro palestino Ziad Abu Ein morreu vítima de um enfrentamento do exército israelense ao grupo que protestava contra a ocupação israelense próximo a Ramallah.

Conjuntura Global, Vol.3, n. 4, out./dez., 2014, p. 184-193. 
UNITED NATIONS - Guidance for Effective Mediation, New York: 2012, p. 26.

Disponível em:

http://www.un.org/wcm/webdav/site/undpa/shared/undpa/pdf/UN Guidance for Effective Mediation.pdf. Acesso em: 14/12/2014. 